\title{
MODEL TARIKAN PERGERAKAN KENDARAAN PADA PUSAT KEGIATAN PENDIDIKAN SEKOLAH MENENGAH KEJURUAN DI BANYUWANGI
}

\author{
Diyah Pratiwi \\ Sugiyanto, Bambang Supriyanto
}

\begin{abstract}
Abstrak: Banyaknya moda kendaraan dapat menimbulkan masalah baru pada Sekolah Menengah Kejuruan yang umumnya tidak memiliki jalur khusus untuk menurunkan penumpang. Perlu dicari model tarikan pergerakan kendaraan yang ditimbulkan oleh banyaknya kendaraan. Penelitian ini untuk mengetahui jumlah tarikan pergerakan kendaraan, karakteristik sosial ekonomi dan perjalanan siswa, guru dan karyawan, serta membuat model tarikan pergerakan kendaraan pada Sekolah Menengah Kejuruan di Banyuwangi. Metode pengumpulan data survey dan kuisioner, analisis statistik dekriptif, analisis korelasi, dan analisis regresi linier berganda. Hasil penelitian jumlah tarikan pergerakan kendaraan di SMKN 1 Glagah Banyuwangi untuk kendaraan bermotor roda 21.292 kendaraan, roda 413 kendaraan, total roda 2 dan roda 41.303 kendaraan, SMKN 1 Banyuwangi untuk kendaraan bermotor roda 21.189 kendaraan, roda 414 kendaraan, total roda 2 dan roda 41.203 kendaraan, SMK PGRI 1 Giri Banyuwangi untuk kendaraan bermotor roda 2 sebanyak 759 kendaraan, roda 410 kendaraan, total roda 2 dan roda 4769 kendaraan, dan SMK Sri Tanjung Banyuwangi untuk kendaraan bermotor roda 2228 kendaraan, roda 48 kendaraan, total roda 2 dan roda 4236 kendaraan. Karakteristik sosial ekonomi dan perjalanan yang mendominasi adalah jumlah kepemilikan sepeda motor 1 unit sebanyak 43,2\%, jumlah kepemilikan mobil 0 unit $83 \%$, jarak tempat

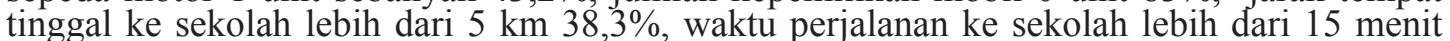
$31 \%$, moda transportasi sepeda motor $91,8 \%$. Model tarikan pergerakan kendaraan yang didapat yaitu (1) tarikan kendaraan roda 2 dan roda $4 \mathrm{Y}=-163,104+0,722 \mathrm{X} 5, \mathrm{R} 2=0,958$; (2) tarikan kendaraan roda $2 \mathrm{Y} 1=-169,085+0,719 \mathrm{X} 5, \mathrm{R} 2=0,957$; (3) tarikan kendaraan roda $4 \mathrm{Y} 2=5,328+0,004 \mathrm{X} 5, \mathrm{R} 2=0,973$; dengan variabel bebas (X5) adalah jumlah siswa.
\end{abstract}

Kata-kata kunci: model, tarikan pergerakan kendaraan, regresi linier berganda, Banyuwangi.

Abstract:The number of vehicle modes can cause new problems in Vocational High Schools which generally do not have special lanes to drop passengers. It is necessary to find a model of the pull of vehicle movement caused by the number of vehicles. This study is to determine the number of vehicle movement traction, socio-economic characteristics and travel of students, teachers and employees, and to make a model of vehicle movement traction at the Vocational High School in Banyuwangi. Survey data collection methods and questionnaires, descriptive statistical analysis, correlation analysis, and multiple linear regression analysis. The results of the study of the number of vehicle movements in the Glagah Banyuwangi 1ND VOCATIONAL SCHOOL for 2-wheeled motor vehicles 1,292 vehicles, 13-wheeled 4 vehicles, total 2-wheeled and 4-wheeled 1,303 vehicles, 1NN Banyuwangi's SMKN for 2-wheeled motorized vehicles 1,189 vehicles, 4-wheeled 14 vehicles, total wheel 2 and 4 wheel 1,203 vehicles, SMK PGRI 1 Giri Banyuwangi for 2 wheeled motor vehicles as many as 759 vehicles, 4 wheeled 10 vehicles, total 2 wheel and 4 wheel 769 vehicles, and SMK Sri Tanjung Banyuwangi for 2 wheel motorized vehicles 228 vehicles, wheels 48 vehicles, total 2 wheels and 4236 wheels. The dominant socio-economic and travel characteristics are $43.2 \%$ of motorcycle ownership 1 unit, 0 units of $83 \%$ car ownership, distance of residence to school more than $5 \mathrm{~km} 38.3 \%$, travel time to school is more than 15 minutes $31 \%$, motorcycle transportation mode 91.8\%. The vehicle movement pull models obtained are (1) 2 wheel and 4 wheel drive vehicles $Y=-163,104+0,722 X 5, R 2=0,958$; (2) the pull of a 2-wheeled vehicle $Y 1=-169.085+0.719 X 5, R 2=0.957$; (3) the pull of a 4 -wheeled vehicle $Y 2=5.328$ $+0.004 X 5, R 2=0.973$; where the independent variable (X5) is the number of students.

Keywords: model, the pull of vehicle movement, multiple linear regression, Banyuwangi.

Diyah Pratiwi adalah Alumni Jurusan Teknik Sipil Fakultas Teknik UM; E-mail: diyah.pratiwi55@gmail.com; Sugiyanto dan Bambang Supriyanto adalah Dosen Jurusan Teknik Sipil Fakultas Teknik Universitas Negeri Malang; Jalan Semarang No.5 Malang 65145; E-mail: sugiyanto.ft@um.ac.id dan bambang.supriyanto.ft@um.ac.id 


\section{PENDAHULUAN}

Tarikan pergerakan adalah jumlah pergerakan yang tertarik pada suatu lokasi tertentu, misalnya keberadaan lokasi sekolah pasti akan menarik orang untuk melakukan kegiatan pendidikan ke tempat tersebut. Tarikan lalu lintas tergantung pada dua aspek tata guna lahan yaitu jenis tata guna lahan, dan jumlah aktivitas dan intensitas pada tata guna lahan tersebut. Jenis tata guna lahan yang berbeda mempunyai ciri pergerakan lalu lintas yang berbeda yaitu jumlah arus lalu lintas, jenis lalu lintas (pejalan kaki, sepeda motor, truk atau mobil), dan lalu lintas pada waktu tertentu (pada sekolah menghasilkan lalu lintas pada pagi saat jam masuk dan siang atau sore pada saat jam pulang).

Menurut Tamin (2000), sebab terjadinya pergerakan dapat dikelompokkan maksud perjalanan. Biasanya maksud perjalanan dikelompokkan sesuai dengan ciri dasarnya, yaitu yang berkaitan dengan ekonomi, sosial, budaya, pendidikan, dan agama. Menurut Munawar (2005), Objek dasar kajian perencanaan transportasi adalah pergerakan manusia atau barang yang pasti melibatkan banyak moda transportasi. Dalam melakukan perjalanan, orang biasanya dihadapkan pada pilihan jenis mobil, angkutan umum, pesawat terbang, atau kereta api. Dalam menentukan pilihan jenis angkutan, orang mempertimbangkan berbagai faktor, yaitu maksud perjalanan, jarak tempuh, biaya, dan tingkat kenyamanan yang biasanya dijadikan keterpengaruhan terhadap pergerakan yang akan terjadi.

Menurut Chaira (2017), banyaknya moda kendaraan tersebut menimbulkan masalah baru dikarenakan sekolah pada umumnya tidak memiliki tempat/jalur khusus untuk menurunkan penumpang baik bagi siswa, guru dan karyawan maupun untuk melepaskan helm dan jaket bagi siswa. Sehingga kendaraan- kendaraan tersebut mau tidak mau berhenti atau parkir di badan jalan sehingga mengurangi kapasitas jalan. Seperti Kapolres Banyuwangi menyebutkan bahwa Bhabinkamtibmas setiap harinya memberikan pelayanan di pagi hari pada kawasan sekolah guna melancarkan arus lalu lintas dan juga mengatasi kemacetan sekaligus mencegah adanya kecelakaan lalu lintas yang bisa menghambat kegiatan belajar mengajar bagi para siswa sekolah.

Kondisi Banyuwangi yang seperti ini membutuhkan perencanaan transportasi yang dikembangkan terutama berkaitan dengan perubahan fungsi tata guna lahan yang akan terjadi. Perencanaan transportasi dapat dilakukan dengan menggunakan konsep pemodelan. Dalam penelitian ini, akan dibuat model matematik tarikan pergerakan pada kondisi sekarang yang ditimbulkan oleh banyaknya kendaraan yang menuju Sekolah Menengah Kejururan di Banyuwangi. Menurut Ortuzar dan Willumsen (2011), model adalah representasi sederhana dari sebuah bagian yang menggambarkan keseluruhan sistem pada dunia nyata yang berfokus pada elemen-elemen yang dianggap penting dalam sebuah sudut pandang sedangkan Simatupang (1995) menjelaskan model sebagai suatu representasi atau formalitas dalam bahasa tertentu yang di sepakati dari suatu kondisi nyata. Model tarikan ini diharapkan dapat digunakan sebagai bahan pertimbangan dalam pengembangan sarana dan prasarana oleh sekolah tersebut serta sebagai bahan pertimbangan menggunakan moda saat menuju ke sekolah.

\section{METODE}

Penelitian ini menggunakan jenis penelitian kuantitatif. Menurut Mikkelsen (2011) penelitian kuantitatif memiliki ciri-ciri isi penelitian kuantitatif dengan hasil penelitian data kuantitatif berupa tabel-tabel, diagram, 
dan angka-angka/data kuantitatif. Setelah dilakukan pengumpulan data maka dilakukan teknik analisis korelasi dan analisis regresilinier data survey untuk membuat prediksi model tarikan pergerakan kendaraan, sedangkan data analisis statistik deskripstif data kuisioner dilakukan untuk mengetahui karakteristik sosial ekonomi dan karakteristik perjalanan. a. Data Primer

Data primer diperoleh dari survei menghitung kendaraan roda 2 dan roda 4 yang menuju ke Sekolah Menengah Kejuruan guna membuat model dan penyebaran kuisioner guna mengetahui karakteristik warga sekolah. Data primer juga diperoleh dengan cara menyebarkan kuisioner kepada siswa, guru, karyawan terkait karakteristik sosial ekonomi dan perjalanan berupa jumlah kepemilikan sepeda motor, jumlah kepemilikan mobil, jarak tempat tinggal ke sekolah, waktu perjalanan, dan moda transportasi yang digunakan. b. Data Sekunder

Data sekunder diperoleh dari survei ke sekolahyangdijadikan sebagailokasipenelitian terkait karakteristik tata guna lahan yaitu total luas lahan (m2), total luas ruang kelas (m2), total luas ruang praktik dan bengkel (m2), jumlah program studi (buah), jumlah siswa (orang), danjumlah guru dan karyawan(orang).

\section{HASIL}

Berdasarkan hasil penelitian yang dilakukan oleh peneliti, didapatkan hasil survey data pokok sekolah dan data tarikan, pengolahan data dari penyebaran angket, serta pemodelan tarikan kendaraan.

\section{Data Pokok Sekolah dan Data Tarikan Kendaraan Sekolah}

\subsection{Data Sekolah}

Data pokok sekolah yang digunakan yaitu data karakteristik tata guna lahan, yang telah didapatkan dari bagian tata usaha sekolah di
Banyuwangi, sekolah-sekolah tersebut yaitu SMKN 1 Glagah Banyuwangi, SMKN 1 Banyuwangi, SMK PGRI 1 Giri Banyuwangi, SMK Sri Tanjung Banyuwangi. Hasil dari survey data pokok sekolah dapat dilihat pada Tabel 3.1 berikut:

\begin{tabular}{|c|c|c|c|c|c|}
\hline No & $\begin{array}{c}\text { Variabel } \\
\text { Bebas }\end{array}$ & $\begin{array}{c}\text { SMKN } \\
1 \\
\text { Glagah } \\
\text { Banyu- } \\
\text { wangi }\end{array}$ & $\begin{array}{c}\text { SMKN } \\
1 \\
\text { Banyu- } \\
\text { wangi }\end{array}$ & $\begin{array}{c}\text { SMK } \\
\text { PGRI } \\
1 \text { Giri } \\
\text { Banyu- } \\
\text { wangi }\end{array}$ & $\begin{array}{c}\text { SMK Sri } \\
\text { Tanjung } \\
\text { Banyu- } \\
\text { wangi }\end{array}$ \\
\hline 1 & $\begin{array}{l}\text { Total luas } \\
\text { lahan } \\
\text { sekolah } \\
(\mathrm{m} 2)\end{array}$ & 35000 & 21911 & 3000 & 4400 \\
\hline 2 & $\begin{array}{l}\text { Total luas } \\
\text { ruang ke- } \\
\text { las (m2) }\end{array}$ & 1890 & 3219 & 4291 & 847 \\
\hline 3 & $\begin{array}{l}\text { Total luas } \\
\text { r.praktik } \\
\text { dan beng- } \\
\text { kel (m2) }\end{array}$ & 6964 & 1316 & 814 & 284 \\
\hline 4 & $\begin{array}{l}\text { Jumlah } \\
\text { program } \\
\text { studi } \\
\text { (buah) }\end{array}$ & 13 & 9 & 5 & 4 \\
\hline 5 & $\begin{array}{l}\text { Jumlah } \\
\text { siswa } \\
\text { (orang) }\end{array}$ & 1971 & 2000 & 1162 & 633 \\
\hline 6 & $\begin{array}{l}\text { Jumlah } \\
\text { guru dan } \\
\text { karyawan } \\
\text { (orang) }\end{array}$ & 160 & 105 & 52 & 35 \\
\hline
\end{tabular}

\subsection{Data Tarikan Kendaraan Sekolah}

Data tarikan kendaraan didapatkan dari survey menghitung jumlah kendaraan bermotor roda 2 dan roda 4 yang menuju ke sekolah. Survey kendaraan dilaksanakan pada tanggal 22 April sampai 26 April 2019 yaitu hari Senin sampai Jumat. Survey dilakukan mulai pukul 05.30 sampai pukul 08.00. Untuk memudahkan surveyor dalam menghitung jumlah tarikan kendaraan maka menggunakan aplikasi di Smartphone yaitu Multicounter. Hasil data tarikan kendaraan SMKN 1 Glagah Banyuwangi dapat dilihat pada Tabel 3.2 berikut: 
Tabel 3.2 Data Tarikan Kendaraan SMKN 1 Glagah Banyuwangi

\begin{tabular}{lccc}
\hline \multirow{2}{*}{ Hari } & \multicolumn{3}{c}{ Jenis Kendaraan } \\
\cline { 2 - 4 } & Roda 2 & Roda 4 & Roda 2 dan Roda 4 \\
\hline Senin & 1274 & 13 & 1287 \\
\hline Selasa & 1292 & 11 & 1303 \\
\hline Rabu & 1287 & 12 & 1299 \\
\hline Kamis & 1283 & 12 & 1295 \\
\hline Jumat & 1272 & 9 & 1281 \\
\hline
\end{tabular}

Berdasarkan Tabel 3.2 hasil survey data kendaraan bermotor roda 2 dan roda 4 yang menuju SMKN 1 Glagah Banyuwangi dalam waktu lima hari menunjukkan jumlah kendaraan terbanyak yaitu untuk kendaraan bermotor roda 2 sebanyak 1292 unit kendaraan, roda 4 sebanyak 13 unit kendaraan, total roda 2 dan roda 4 sebanyak 1303 unit kendaraan. Hasil data tarikan kendaraan SMKN 1 Banyuwangi dapat dilihat pada Tabel 3.3 Banyuwangi berikut:

Tabel 3.3 Data Tarikan Kendaraan SMKN 1 Banyuwangi

\begin{tabular}{lccc}
\hline \multirow{2}{*}{ Hari } & \multicolumn{3}{c}{ Jenis Kendaraan } \\
\cline { 2 - 4 } & Roda 2 & Roda 4 & Roda 2 dan Roda 4 \\
\hline Senin & 1171 & 13 & 1184 \\
\hline Selasa & 1189 & 14 & 1203 \\
\hline Rabu & 1169 & 13 & 1180 \\
\hline Kamis & 1152 & 12 & 1165 \\
\hline Jumat & 1173 & 13 & 1186 \\
\hline
\end{tabular}

Berdasarkan Tabel 3.3 hasil survey data kendaraan bermotor roda 2 dan dan roda 4 yang menuju SMKN 1 Banyuwangi dalam waktu lima hari menunjukkan jumlah kendaraan terbanyak yaitu roda 2 sebanyak 1189 unit kendaraan, roda 4 sebanyak 14 unit kendaraan, dan total roda 2 dan roda 4 sebanyak 1203 unit kendaraan. Hasil data tarikan kendaraan SMK PGRI 1 Giri Banyuwangi dapat dilihat pada Tabel 3.4 berikut:

Tabel 3.4 Data Tarikan Kendaraan SMK PGRI 1 Giri Banyuwangi

\begin{tabular}{llll}
\hline \multirow{2}{*}{ Hari } & \multicolumn{3}{c}{ Jenis Kendaraan } \\
\cline { 2 - 4 } & Roda 2 & Roda 4 & Roda 2 dan Roda 4 \\
\hline Senin & 750 & 9 & 759 \\
\hline Selasa & 738 & 6 & 744 \\
\hline Rabu & 740 & 7 & 747 \\
\hline Kamis & 759 & 10 & 769 \\
\hline Jumat & 748 & 7 & 755 \\
\hline
\end{tabular}

Berdasarkan Tabel 3.4 hasil survey data kendaraan bermotor roda 2 dan dan roda 4 yang menuju SMK PGRI 1 Giri Banyuwangi dalam waktu lima hari menunjukkan jumlah kendaraan terbanyak yaitu roda 2 sebanyak 759 unit kendaraan, roda 4 sebanyak 10 unit kendaraan, dan total roda 2 dan roda 4 sebanyak 769 unit kendaraan. Hasil data tarikan kendaraan SMK Sri Tanjung Banyuwangi dapat dilihat pada Tabel 3.5 berikut:

Tabel 3.5 Data Tarikan Kendaraan SMK Sri Tanjung Banyuwangi

\begin{tabular}{lccc}
\hline \multirow{2}{*}{ Hari } & \multicolumn{3}{c}{ Jenis Kendaraan } \\
\cline { 2 - 4 } & Roda 2 & Roda 4 & Roda 2 dan Roda 4 \\
\hline Senin & 750 & 9 & 759 \\
\hline Selasa & 738 & 6 & 744 \\
\hline Rabu & 740 & 7 & 747 \\
\hline Kamis & 759 & 10 & 769 \\
\hline Jumat & 748 & 7 & 755 \\
\hline
\end{tabular}

Berdasarkan Tabel 3.5 hasil survey data kendaraan bermotor roda 2 dan dan roda 4 yang menuju SMK Sri Tanjung Banyuwangi dalam waktu lima hari menunjukkan bahwa jumlah kendaraan terbanyak yaitu roda 2 sebanyak 228 unit kendaraan, roda 4 sebanyak 8 unit kendaraan, dan total roda 2 dan roda 4 sebanyak 236 unit kendaraan.

\section{Data Hasil Karakteristik Sosial Ekonomi dan Karakteristik Perjalanan}

Proses penyebaran kuisioner guna untuk menjawab karakteristik responden terkait karakteristik sosial ekonomi dan karakteristik perjalanan dengan jumlah sampel sebanyak 329 responden dari jumlah populasi sebanyak 6118 responden. Menurut Sugiyono (2015), sampel adalah bagian dari jumlah dan karakteristik yang dimiliki oleh populasi. Sehingga hasil yang didapat akan diketahui bahwa bagaimana kondisi sosial ekonomi responden dan perjalanan yang dilakukan oleh responden yang kemungkinan akan mempengaruhi responden untuk membawa berbagai moda kendaraan untuk menuju ke sekolah. Hasil dari karakteristik pelaku perjalanan selaku responden yang mendominasi dalam penelitian ini dapat dilihat pada Tabel 3.6 berikut ini: 


\begin{tabular}{|c|l|c|c|c|}
\hline \multicolumn{5}{|c|}{ Tabel 3.6 Hasil Karakteristik Sosial Ekonomi } \\
dan Karakteristik Perjalanan \\
\hline No & \multicolumn{1}{|c|}{ Variabel } & $\begin{array}{l}\text { Karak- } \\
\text { teristik }\end{array}$ & $\begin{array}{c}\text { Frekue- } \\
\text { nsi (F) }\end{array}$ & $\begin{array}{c}\text { Prosen- } \\
\text { tase (\%) }\end{array}$ \\
\hline 1 & $\begin{array}{l}\text { Jumlah Kepe- } \\
\text { milikan Sepeda } \\
\text { Motor }\end{array}$ & 1 unit & 142 & 43.2 \\
\hline 2 & $\begin{array}{l}\text { Jumlah Kepe- } \\
\text { milikan Mobil }\end{array}$ & 0 unit & 273 & 83 \\
\hline 3 & $\begin{array}{l}\text { Jarak Tempat } \\
\text { Tinggal ke } \\
\text { Sekolah }\end{array}$ & $>15$ km & 126 & 38.3 \\
\hline 4 & $\begin{array}{l}\text { Waktu Perjala- } \\
\text { nan ke Sekolah }\end{array}$ & $>15$ menit & 102 & 31 \\
\hline 5 & $\begin{array}{l}\text { Moda Trans- } \\
\text { portasi Yang } \\
\text { Digunakan }\end{array}$ & $\begin{array}{l}\text { Sepeda } \\
\text { Motor }\end{array}$ & 302 & 91.8 \\
\hline
\end{tabular}

\section{Hasil Model Tarikan Pergerakan Kenda-} raan

Analisis data bertujuan untuk menghasilkan suatu model persamaan regresi antara variabel terikat (Y) dengan variabel bebas (X). Sebelum dapat menentukan sebuah model terlebih dahulu dilakukan uji asumsi klasik, uji asumsi klasik harus dilakukan pengujianya karena untuk memenuhi penggunaan regresi linier berganda. Menurut Widiarti (2017) Uji asumsi klasik yang sering digunakan yaitu uji normalitas, uji linearitas, uji multikolinearitas, dan uji heteroskedastisitas. Setelah data dinyatakan lolos uji asumsi klasik selanjutnya melakukan analisis korelasi dan disambung dengan analisis regresi linier untuk memperoleh model yang diinginkan. Data selengkapnya dapat dilihat pada Tabel 3.7 Input Data Primer dan Sekunder berikut:

\section{Tabel 3.7 Input Data Primer dan Sekunder}

\begin{tabular}{|c|c|c|c|c|c|c|c|c|c|}
\hline $\begin{array}{l}\text { Variabel } \\
\text { Bebas }\end{array}$ & $\begin{array}{c}\text { Jumlah } \\
\text { Tarikan } \\
\text { R2 \& } \\
\text { R4 }\end{array}$ & $\begin{array}{c}\text { Jumlah } \\
\text { Tarikan } \\
\text { R2 }\end{array}$ & $\begin{array}{c}\text { Jumlah } \\
\text { Tarikan } \\
\text { R4 }\end{array}$ & $\begin{array}{c}\text { Total } \\
\text { Luas } \\
\text { Lahan } \\
(\mathrm{m} 2)\end{array}$ & $\begin{array}{c}\text { Total } \\
\text { Luas } \\
\text { Kelas } \\
(\mathrm{m} 2)\end{array}$ & $\begin{array}{c}\text { Total Luas } \\
\text { Bengkel } \\
\text { R.praktik } \\
\text { (m2) }\end{array}$ & $\begin{array}{c}\text { Jumlah } \\
\text { Pro- } \\
\text { gram } \\
\text { Studi } \\
\text { (buah) }\end{array}$ & $\begin{array}{c}\text { Jumlah } \\
\text { Siswa } \\
\text { (orang) }\end{array}$ & $\begin{array}{c}\text { Jumlah } \\
\text { Guru \& } \\
\text { Karyawan } \\
\text { (orang) }\end{array}$ \\
\hline & $Y$ & Y1 & Y2 & X1 & $\mathrm{X} 2$ & X3 & X4 & X5 & X6 \\
\hline $\begin{array}{l}\text { SMKN } 1 \text { Gl- } \\
\text { agah Banyu- } \\
\text { wangi }\end{array}$ & 1303 & 1292 & 13 & 35000 & 1890 & 6964 & 13 & 1971 & 160 \\
\hline $\begin{array}{l}\text { SMKN } 1 \\
\text { Banyuwangi }\end{array}$ & 1203 & 1189 & 14 & 21911 & 3219 & 1316 & 9 & 2000 & 105 \\
\hline $\begin{array}{l}\text { SMK PGRI } 1 \\
\text { Giri Banyu- } \\
\text { wangi }\end{array}$ & 769 & 759 & 10 & 3000 & 4291 & 814 & 5 & 1162 & 52 \\
\hline $\begin{array}{l}\text { SMK Sri Tan- } \\
\text { jung Banyu- } \\
\text { wangi }\end{array}$ & 236 & 228 & 8 & 4400 & 847 & 284 & 4 & 633 & 35 \\
\hline
\end{tabular}

\subsection{Uji Normalitas}

Uji Normal Probability Plot (Uji P-Plot) menjadi salah satu alternative yang cukup efektif untuk mendeteksi apakah data yang akan dianalisis berdistribusi normal atau tidak. Menurut Raharjo S (2017), untuk melihat kenormalan suatu nilai residual dapat berpedoman dari titik-titik yang ada dari hasil output SPSS dengan ketentuan jika titik-titik berada didekat garis diagonalnya maka dikatakan bahwa nilai residual berdistribusi normal begitupula sebaliknya. Sehingga dapat dilihat Tabel 3.8 Hasil Uji Normal P-Plot menunjukkan bahwa nilai residual berdistribusi normal.

\begin{tabular}{|c|c|c|c|}
\hline \multicolumn{4}{|c|}{ Tabel 3.8 Hasil Uji Normal P-Plot } \\
\hline No & $\begin{array}{l}\text { Variabel } \\
\text { Terikat }\end{array}$ & Hasil & Kesimpulan \\
\hline 1 & $\begin{array}{l}\text { Kendaraan } \\
\text { Roda } 2 \text { dan } \\
\text { Roda } 4\end{array}$ & $\begin{array}{l}\text { Titik- } \\
\text { titik berada } \\
\text { didekat } \\
\text { garis di- } \\
\text { agonal }\end{array}$ & $\begin{array}{l}\text { Berdistribusi } \\
\text { normal }\end{array}$ \\
\hline 2 & $\begin{array}{l}\text { Kendaraan } \\
\text { Roda } 2\end{array}$ & $\begin{array}{l}\text { Titik- } \\
\text { titik berada } \\
\text { didekat } \\
\text { garis di- } \\
\text { agonal }\end{array}$ & $\begin{array}{l}\text { Berdistribusi } \\
\text { normal }\end{array}$ \\
\hline 3 & $\begin{array}{l}\text { Kendaraan } \\
\text { Roda } 4\end{array}$ & $\begin{array}{l}\text { Titik- } \\
\text { titik berada } \\
\text { didekat } \\
\text { garis di- } \\
\text { agonal }\end{array}$ & $\begin{array}{l}\text { Berdistribusi } \\
\text { normal }\end{array}$ \\
\hline
\end{tabular}




\subsection{Uji Linearitas}

Sebuah model regresi dikatakan baik apabila ada hubungan yang linier antara satu variabel independent $(\mathrm{Xn})$ dengan satu variabel dependent (Y). Liniearitas dimaknai sebagai hubungan antar variabel seperti garis lurus atau membentuk pola garis liniear. Salah satu cara untuk mendeteksi ada tidaknya hubungan yang liniear antar variabel ini dapat dilakukan dengan teknik grafik scatter plot. Dapat dilihat pada Tabel 3.9 Hasil Uji Linearitas menunjukkan bahwa hasil uji linieartas yang liniear dan positif karena titik-titik plot data membentuk pola garis lurus dari kiri bawah naik ke kanan atas sehingga apabila nilai $\mathrm{X}$ meningkat maka nilai $\mathrm{Y}$ juga meningkat.

Tabel 3.9 Hasil Uji Linearitas Teknik Grafik Scatter Plot

\begin{tabular}{cccc}
\hline No & Variabel & Hasil & Kesimpulan \\
\hline 1 & Y terhadap X1 & Pola garis lurus & Linear positif \\
\hline 2 & Y terhadap X2 & Pola garis lurus & Linear positif \\
\hline 3 & Y terhadap X3 & Pola garis lurus & Linear positif \\
\hline 4 & Y terhadap X4 & Pola garis lurus & Linear positif \\
\hline 5 & Y terhadap X5 & Pola garis lurus & Linear positif \\
\hline 6 & Y terhadap X6 & Pola garis lurus & Linear positif \\
\hline 7 & Y1 terhadap X1 & Pola garis lurus & Linear positif \\
\hline 8 & Y1 terhadap X2 & Pola garis lurus & Linear positif \\
\hline 9 & Y1 terhadap X3 & Pola garis lurus & Linear positif \\
\hline 10 & Y1 terhadap X4 & Pola garis lurus & Linear positif \\
\hline 11 & Y1 terhadap X5 & Pola garis lurus & Linear positif \\
\hline 12 & Y1 terhadap X6 & Pola garis lurus & Linear positif \\
\hline 13 & Y2 terhadap X1 & Pola garis lurus & Linear positif \\
\hline 14 & Y2 terhadap X2 & Pola garis lurus & Linear positif \\
\hline 15 & Y2 terhadap X3 & Pola garis lurus & Linear positif \\
\hline 16 & Y2 terhadap X4 & Pola garis lurus & Linear positif \\
\hline 17 & Y2 terhadap X5 & Pola garis lurus & Linear positif \\
\hline 18 & Y2 terhadap X6 & Pola garis lurus & Linear positif \\
\hline & & &
\end{tabular}

\subsection{Uji Multikolinearitas}

Uji multikolinearitas adalah untuk melihat ada atau tidaknya korelasi yang tinggi antara variabel-variabel bebas dalam suatu model regresi linear berganda Model regresi yang baik seharusnya tidak terjadi korelasi diantara variabel bebas atau tidak terjadi gejala multikolin earitas. Menurut Priyatno (2009:152), untuk mendeteksi ada tidaknya gejala multikolinearitas dalam model regresi, maka dapat dilaku kan salah satunya dengan cara melihat nilai tolerance dan nilai Variance Inflating Factor (VIF). Hasil nilai tolerance lebih besar dari 0,10 artinya tidak terjadi multikolinearitas. Sedangkan hasil nilai VIF kurang dari 10,00 artinya tidak terjadi multikolinearitas. Jadi kedua dasar pengambilan keputusan menyatakan bahwa tidak terjadi gejala multikolinearitas dalam model regresi. Hasil Uji Multikolinearitas dapat dilihat pada Tabel 3.10 berikut:

Tabel 3.10 Hasil Uji Multikolinearitas berdasarkan Tolerance dan VIF

\begin{tabular}{|c|c|c|c|c|}
\hline \multirow[t]{2}{*}{ No } & \multirow[t]{2}{*}{ Variabel } & \multicolumn{2}{|c|}{ Hasil } & \multirow[t]{2}{*}{ Kesimpulan } \\
\hline & & $\begin{array}{c}\text { Tolerance } \\
>0,10\end{array}$ & $\underset{10}{\mathrm{VIF}<}$ & \\
\hline 1 & Y terhadap X1 & 0.249 & 4.017 & $\begin{array}{l}\text { Tidak terjadi gejala } \\
\text { multikolinearitas }\end{array}$ \\
\hline 2 & Y terhadap X2 & 0.907 & 1.102 & $\begin{array}{l}\text { Tidak terjadi gejala } \\
\text { multikolinearitas }\end{array}$ \\
\hline 3 & Y terhadap X3 & 0.59 & 1.694 & $\begin{array}{l}\text { Tidak terjadi gejala } \\
\text { multikolinearitas }\end{array}$ \\
\hline 4 & Y terhadap X4 & 0.212 & 4.725 & $\begin{array}{l}\text { Tidak terjadi gejala } \\
\text { multikolinearitas }\end{array}$ \\
\hline 5 & Y terhadap X5 & 1 & 1 & $\begin{array}{l}\text { Tidak terjadi gejala } \\
\text { multikolinearitas }\end{array}$ \\
\hline 6 & Y terhadap X6 & 0.203 & 4.924 & $\begin{array}{l}\text { Tidak terjadi gejala } \\
\text { multikolinearitas }\end{array}$ \\
\hline 7 & Y1 terhadap X1 & 0.249 & 4.017 & $\begin{array}{l}\text { Tidak terjadi gejala } \\
\text { multikolinearitas }\end{array}$ \\
\hline 8 & Y1 terhadap X2 & 0.907 & 1.102 & $\begin{array}{l}\text { Tidak terjadi gejala } \\
\text { multikolinearitas }\end{array}$ \\
\hline 9 & Y1 terhadap X3 & 0.59 & 1.694 & $\begin{array}{l}\text { Tidak terjadi gejala } \\
\text { multikolinearitas }\end{array}$ \\
\hline 10 & Y1 terhadap X4 & 0.212 & 4.725 & $\begin{array}{l}\text { Tidak terjadi gejala } \\
\text { multikolinearitas }\end{array}$ \\
\hline 11 & Y1 terhadap X5 & 1 & 1 & $\begin{array}{l}\text { Tidak terjadi gejala } \\
\text { multikolinearitas }\end{array}$ \\
\hline 12 & Y1 terhadap X6 & 0.203 & 4.924 & $\begin{array}{l}\text { Tidak terjadi gejala } \\
\text { multikolinearitas }\end{array}$ \\
\hline 13 & Y2 terhadap X1 & 0.249 & 4.017 & $\begin{array}{l}\text { Tidak terjadi gejala } \\
\text { multikolinearitas }\end{array}$ \\
\hline 14 & Y2 terhadap X2 & 0.907 & 1.102 & $\begin{array}{l}\text { Tidak terjadi gejala } \\
\text { multikolinearitas }\end{array}$ \\
\hline 15 & Y2 terhadap X3 & 0.59 & 1.694 & $\begin{array}{l}\text { Tidak terjadi gejala } \\
\text { multikolinearitas }\end{array}$ \\
\hline 16 & Y2 terhadap X4 & 0.212 & 4.725 & $\begin{array}{l}\text { Tidak terjadi gejala } \\
\text { multikolinearitas }\end{array}$ \\
\hline 17 & Y2 terhadap X5 & 1 & 1 & $\begin{array}{l}\text { Tidak terjadi gejala } \\
\text { multikolinearitas }\end{array}$ \\
\hline 18 & Y2 terhadap X6 & 0.203 & 4.924 & $\begin{array}{l}\text { Tidak terjadi gejala } \\
\text { multikolinearitas }\end{array}$ \\
\hline
\end{tabular}




\subsection{Uji Heteroskedastisitas}

Uji heteroskedastisitas berfungsi untuk menguji terjadinya perbedaan variance dari nilai residual pada suatu periode pengamatan yang lainnya. Model regresi yang baik seharusnya tidak terjadi gejala heteroskedastisitas. Hasil Uji Heteroskedastisitas dapat dilihat pada Tabel 3.11 berikut:

\begin{tabular}{|c|c|c|c|}
\hline No & $\begin{array}{l}\text { Variabel } \\
\text { Terikat }\end{array}$ & Hasil & $\underset{\text { lan }}{\text { Kesimpu- }}$ \\
\hline 1 & $\begin{array}{l}\text { Kendaraan } \\
\text { Roda } 2 \text { dan } \\
\text { Roda } 4\end{array}$ & $\begin{array}{l}\text { Titik-titik data } \\
\text { tidak berpola dan } \\
\text { menyebar }\end{array}$ & $\begin{array}{l}\text { Tidak terjadi } \\
\text { heteroske- } \\
\text { dastisitas }\end{array}$ \\
\hline 2 & $\begin{array}{l}\text { Kendaraan } \\
\text { Roda } 2\end{array}$ & $\begin{array}{l}\text { Titik-titik data } \\
\text { tidak berpola dan } \\
\text { menyebar }\end{array}$ & $\begin{array}{l}\text { Tidak terjadi } \\
\text { heteroske- } \\
\text { dastisitas }\end{array}$ \\
\hline 3 & $\begin{array}{l}\text { Kendaraan } \\
\text { Roda } 4\end{array}$ & $\begin{array}{l}\text { Titik-titik data } \\
\text { tidak berpola dan } \\
\text { menyebar }\end{array}$ & $\begin{array}{l}\text { Tidak terjadi } \\
\text { heteroske- } \\
\text { dastisitas }\end{array}$ \\
\hline
\end{tabular}

\subsection{Uji Analisis Korelasi}

Untuk mengetahui variabel bebas (X) yang dapat berpengaruh pada variabel terikat (Y) dilakukan uji korelasi mendapat hasil sesuai pengambilan keputusan $r$ hitung $>r$ tabel maka ada korelasi antar variabel. Sebaliknya jika nilai $r$ hitung $<\mathrm{r}$ tabel maka artinya tidak terjadi korelasi antar variabel. Jika koefisien korelasi positif, maka kedua variabel mempunyai hubungan searah. Artinya jika nilai variabel X tinggi, maka nilai variabel $Y$ akan tinggi. Jika koefisien korelasi negatif, maka kedua variabel mempuyai hubungan terbalik. Artinya jika nilai variabel $X$ tinggi, maka nilai variabel $Y$ akan menjadi rendah dan berlaku sebaliknyaHasil tersebut dapat dilihat pada Tabel 3.12 untuk Hasil Rekapitulasi Analisis Korelasi .

\subsection{Uji Analisis Regresi Linier}

Untuk analisis data agar mendapat model yaitu analisis regresi linier dengan bantuan program SPSS 22.0 dengan asumsi harus dilakukan uji serempak (uji F) dapat dilihat pada Tabel 3.13 dan uji secara parsial (uji t) dapat dilihat pada Tabel 3.14 yang gunanya untuk mengetahui hipotesis diterima atau ditolak, kemudian jika sudah diketahui hipotesis yang diterima antara variabel terikat terhadap variabel bebas maka langkah berikutnya melakukan uji determinasi (R2) dapat dilihat pada Tabel 3.15 yang berfungsi untuk mengetahui sejauh mana ketepatan model regresi yang terbentuk.
Tabel 3.12 Hasil Rekapitulasi Analisis Korelasi

\begin{tabular}{|c|c|c|c|c|}
\hline \multirow{2}{*}{ No } & \multirow{2}{*}{ Variabel } & \multicolumn{2}{|c|}{ Hasil } & \multirow{2}{*}{ Kesimpular } \\
\hline & & r hitung & $r$ tabel & \\
\hline 1 & Y terhadap X1 & 0.846 & 0.8114 & Ada korelasi \\
\hline 2 & Y terhadap X2 & 0.382 & 0.8114 & $\begin{array}{l}\text { Tidak ada ko- } \\
\text { relasi }\end{array}$ \\
\hline 3 & Y terhadap X3 & 0.687 & 0.8114 & $\begin{array}{l}\text { Tidak ada ko- } \\
\text { relasi }\end{array}$ \\
\hline 4 & Y terhadap X4 & 0.89 & 0.8114 & Ada korelasi \\
\hline 5 & Y terhadap X5 & 0.986 & 0.8114 & Ada korelasi \\
\hline 6 & Y terhadap X6 & 0.898 & 0.8114 & Ada korelasi \\
\hline 7 & Y1 terhadap X1 & 0.847 & 0.8114 & Ada korelasi \\
\hline 8 & Y1 terhadap X2 & 0.381 & 0.8114 & $\begin{array}{l}\text { Tidak ada ko- } \\
\text { relasi }\end{array}$ \\
\hline 9 & Y1 terhadap X3 & 0.689 & 0.8114 & $\begin{array}{l}\text { Tidak ada ko- } \\
\text { relasi }\end{array}$ \\
\hline 10 & Y1 terhadap X4 & 0.891 & 0.8114 & Ada korelasi \\
\hline 11 & Y1 terhadap X5 & 0.986 & 0.8114 & Ada korelasi \\
\hline 12 & Y1 terhadap X6 & 0.899 & 0.8114 & Ada korelasi \\
\hline 13 & Y2 terhadap X1 & 0.82 & 0.8114 & Ada korelasi \\
\hline 14 & Y2 terhadap X2 & 0.325 & 0.8114 & $\begin{array}{l}\text { Tidak ada ko- } \\
\text { relasi }\end{array}$ \\
\hline 15 & Y2 terhadap X3 & 0.54 & 0.8114 & $\begin{array}{l}\text { Tidak ada ko- } \\
\text { relasi }\end{array}$ \\
\hline 16 & Y2 terhadap X4 & 0.831 & 0.8114 & Ada korelasi \\
\hline 17 & Y2 terhadap X5 & 0.991 & 0.8114 & Ada korelasi \\
\hline 18 & Y2 terhadap X6 & 0.835 & 0.8114 & Ada korelasi \\
\hline
\end{tabular}

Tabel 3.13 Hasil Uji Serempak (Uji-F)

\begin{tabular}{|c|c|c|c|c|c|c|c|}
\hline \multicolumn{2}{|c|}{ Model } & $\begin{array}{c}\text { Sum of } \\
\text { Squares }\end{array}$ & df & $\begin{array}{l}\text { Mean } \\
\text { Square }\end{array}$ & $\mathbf{F}$ & Sig. & $\begin{array}{c}\text { Kes- } \\
\text { imp- } \\
\text { ulan } \\
\text { Sig } \\
<0.05\end{array}$ \\
\hline \multirow[t]{3}{*}{ Y } & $\begin{array}{l}\text { Re- } \\
\text { gres- } \\
\text { sion }\end{array}$ & 690344.37 & 1 & 690344.37 & 69.206 & $.014 \mathrm{~b}$ & Lolos \\
\hline & $\begin{array}{l}\text { Re- } \\
\text { sidual }\end{array}$ & 19950.38 & 2 & 9975.19 & & & \\
\hline & Total & 710294.75 & 3 & & & & \\
\hline \multirow[t]{3}{*}{$\mathrm{Y} 1$} & $\begin{array}{l}\text { Re- } \\
\text { gres- } \\
\text { sion }\end{array}$ & 684032.87 & 1 & 684032.87 & 67.522 & $.014 \mathrm{~b}$ & Lolos \\
\hline & $\begin{array}{l}\text { Re- } \\
\text { sidual }\end{array}$ & 20261.13 & 2 & 10130.565 & & & \\
\hline & Total & 704294 & 3 & & & & \\
\hline \multirow[t]{3}{*}{ Y2 } & $\begin{array}{l}\text { Re- } \\
\text { gres- } \\
\text { sion }\end{array}$ & 22.346 & 1 & 22.346 & 110.657 & $.009 b$ & Lolos \\
\hline & $\begin{array}{l}\text { Re- } \\
\text { sidual }\end{array}$ & 0.404 & 2 & 0.202 & & & \\
\hline & Total & 22.75 & 3 & & & & \\
\hline
\end{tabular}


Uji F pada prinsipnya bertujuan untuk mengetahui pengaruh dari 2 (dua) variabel bebas atau lebih secara simultan (bersama) terhadap variabel terikat. Dasar pengambilan keputusan untuk uji f membandingkan nilai signifikansi atau nilai probabilitas dari hasil perhitungan SPSS apakahnilai signifikansitersebutlebih besar atau lebih kecil dari nilai standar yakni 0,05.

Tabel 3.14 Hasil Uji Parsial (Uji-T)

\begin{tabular}{|c|c|c|c|c|c|c|c|}
\hline & \multirow[t]{2}{*}{ Model } & \multicolumn{2}{|c|}{$\begin{array}{l}\text { Unstandardized } \\
\text { Coefficients }\end{array}$} & \multirow{2}{*}{$\begin{array}{c}\begin{array}{c}\text { Stan- } \\
\text { dard- } \\
\text { ized } \\
\text { Coeffi- } \\
\text { cients }\end{array} \\
\text { Beta }\end{array}$} & \multirow[t]{2}{*}{ t } & \multirow[t]{2}{*}{ Sig. } & \multirow[t]{2}{*}{$\begin{array}{c}\text { Kes- } \\
\text { im- } \\
\text { pulan } \\
\text { Sig } \\
<0.05\end{array}$} \\
\hline & & B & $\begin{array}{l}\text { Std. } \\
\text { Error }\end{array}$ & & & & \\
\hline \multirow[t]{2}{*}{ Y } & (Constant) & -163.104 & 134.715 & & -1.211 & 0.35 & Lolos \\
\hline & $\begin{array}{l}\text { Jumlah } \\
\text { Siswa } \\
\text { (X5) }\end{array}$ & 0.722 & 0.087 & 0.986 & 8.319 & 0.014 & \\
\hline \multirow[t]{2}{*}{ Y1 } & (Constant) & -169.085 & 135.76 & & -1.245 & 0.339 & Lolos \\
\hline & $\begin{array}{l}\text { Jumlah } \\
\text { Siswa } \\
\text { (X5) }\end{array}$ & 0.719 & 0.087 & 0.986 & 8.217 & 0.014 & \\
\hline \multirow[t]{2}{*}{ Y2 } & (Constant) & 5.328 & 0.606 & & 8.79 & 0.013 & Lolos \\
\hline & $\begin{array}{l}\text { Jumlah } \\
\text { Siswa } \\
\text { (X5) }\end{array}$ & 0.004 & 0 & 0.991 & 10.519 & 0.009 & \\
\hline
\end{tabular}

Uji t bertujuan untuk mengetahui apakah variabel bebas (X) secara parsial (sendiri) berpengaruh signifikan terhadap variabel (Y). Dasar pengambilan keputusan untuk Uji $\mathrm{t}$ membandingkan nilai signifikansi atau nilai probabilitas dari hasil perhitungan SPSS apakah nilai signifikansi tersebut lebih besar atau lebih kecil dari nilai standar yakni 0,05 .

Tabel 3.15 Hasil Uji Determinasi (R2)

\begin{tabular}{llllll}
\hline Model & R & \multicolumn{1}{c}{$\begin{array}{c}\text { R } \\
\text { Square }\end{array}$} & $\begin{array}{c}\text { Ad- } \\
\text { justed } \\
\text { R } \\
\text { Square }\end{array}$ & $\begin{array}{c}\text { Std. Er- } \\
\text { ror of the } \\
\text { Estimate }\end{array}$ \\
\hline Y & $\begin{array}{l}\text { Jumlah } \\
\text { Siswa } \\
\text { (X5) }\end{array}$ & 0.986 & 8.319 & 0.958 & 99.876 \\
\hline Y1 & $\begin{array}{l}\text { Jumlah } \\
\text { Siswa } \\
\text { (X5) }\end{array}$ & 0.986 & 8.217 & 0.957 & 100.651 \\
\hline Y2 & $\begin{array}{l}\text { Jumlah } \\
\text { Siswa } \\
\text { (X5) }\end{array}$ & 0.991 & 10.519 & 0.973 & 0.449 \\
\hline
\end{tabular}

Koefisien determinasi ( $\mathrm{R}$ square atau $\mathrm{R}$ kuadrat) atau disimbolkan dengan "R2" yang bermakna sebagai sumbangan pengaruh yang diberikan variabel bebas (X) terhadap variabel terikat $(\mathrm{Y})$ atau dengan kata lain nilai koefisien determinasi berguna untuk memprediksi dan melihat seberapa besar kontribusi pengaruh yang diberikan variabel $\mathrm{X}$ terhadap variabel Y. Dengan demikian hasil analisis regresi linier yang didapatkan setelah dilakukannya berbagai pengujian seperti pada Tabel 3.16 Hasil Analisis Regresi Linier berikut:

Tabel 3.16 Hasil Regresi Linier Berganda

\begin{tabular}{clc}
\hline No & Model Persamaan Regresi & R2 \\
\hline 1 & $\mathrm{Y}=-163,104+0,722 \mathrm{X} 5$ & 0,958 \\
\hline 2 & $\mathrm{Y} 1=-176,021+0,700 \mathrm{X} 5$ & 0,957 \\
\hline 3 & $\mathrm{Y} 2=5,240+0,003 \mathrm{X} 5$ & 0,973 \\
\hline
\end{tabular}

\section{PEMBAHASAN}

\section{Tarikan Kendaraan Sekolah}

Berdasarkan hasil penelitian menunjukkan jumlah tarikan pergerakan kendaraan di SMKN 1 Glagah Banyuwangi untuk kendaraan bermotor roda 2 sebanyak 1.292 kendaraan, roda 4 sebanyak 13 kendaraan, total roda 2 dan roda 4 sebanyak 1.303 kendaraan, SMKN 1 Banyuwangi untuk kendaraan bermotor roda 2 sebanyak 1.189 kendaraan, roda 4 sebanyak 14 kendaraan, total roda 2 dan roda 4 sebanyak 1.203 kendaraan, SMK PGRI 1 Giri Banyuwangi untuk kendaraan bermotor roda 2 sebanyak 759 kendaraan, roda 4 sebanyak 10 kendaraan, total roda 2 dan roda 4 sebanyak 769 kendaraan, dan SMK Sri Tanjung Banyuwangi untuk kendaraan bermotor roda 2 sebanyak 228 kendaraan, roda 4 sebanyak 8 kendaraan, total roda 2 dan roda 4 sebanyak 236 kendaraan.

\section{Karakteristik Sosial Ekonomi dan Perjala- nan}

Berdasarkan hasil penelitian diatas dapat dapat diperoleh bahwa karakteristik sosial ekonomi dan perjalanan yang mendominasi adalah jumlah kepemilikan sepeda motor 1 unit dengan frekuensi 142 responden prosentase 
43,2\%, jumlah kepemilikan mobil 0 unit dengan frekuensi 273 responden prosentase $83 \%$, jarak tempat tinggal ke sekolah yang lebih dari $5 \mathrm{~km}$ dengan frekuensi 126 responden prosentase $38,3 \%$, waktu perjalanan ke sekolah yang ditempuh lebih dari 15 menit dengan frekuensi 102 responden prosentase $31 \%$, moda transportasi menggunakan sepeda motor dengan frekuensi 301 responden prosentase 91,8\%.

\section{Model Tarikan Pergerakan Kendaraan 1. Kendaraan Roda 2 dan Roda 4}

Model persamaan tarikan kendaraan roda 2 dan roda 4 yaitu $\mathrm{Y}=-163,104+0,722 \mathrm{X} 5$ mendapatkan hasil uji serempak (uji F) menghasilkan angka signifikansi seperti pada Tabel 3.13 yaitu sebesar 0,014 . Maka model analisis regresi pembentuk model lolos uji $\mathrm{F}$, dan dapat dikatakan signifikan. Kemudian berdasarkan pada Tabel 3.14 dapat diketahui bahwa hasil uji parsial (Uji t) bahwa angka signifikansi variabel bebas jumlah siswa (X5) sebesar 0,014 . Maka dapat disimpulkan bahwa variabel bebas jumlah siswa menghasilkan angka dibawah 0,05 , yang mana dapat diartikan pembentuk model lolos uji t. Sehingga berdasarkan hasil yang diperoleh dapat diambil keputusan bahwa variabel jumlah siswa (X5) berpengaruh secara signifikan terhadap variabel jumlah tarikan kendaraan roda 2 dan roda $4(\mathrm{Y})$. Berdasarkan Tabel 3.15 diketahui model yang didapat memiliki harga koefisien determinasi (R2) Adjusted R Square sebesar 0,958. Hal tersebut menunjukkan sebanyak $95,8 \%$ jumlah tarikan pergerakan kendaraan roda 2 dan roda 4 dipengaruhi oleh jumlah siswa. Sedangkan sisanya $4,2 \%$ dijelaskan oleh variabel-variabel yang tidak dibahas dalam penelitian ini.

\section{Tarikan Kendaraan Roda 2}

Model persamaan tarikan kendaraan roda 2 yaitu Y1 $=-169,085+0,719 X 5$ mendapatkan hasil uji serempak (uji F) menghasilkan angka signifikansi seperti pada Tabel 3.13 yaitu sebesar 0,014. Maka model analisis re- gresi pembentuk model lolos uji $\mathrm{F}$, dan dapat dikatakan signifikan. Kemudian berdasarkan pada Tabel 3.14 dapat diketahui bahwa hasil uji parsial (Uji t) bahwa angka signifikansi variabel bebas jumlah siswa (X5) sebesar 0,014 . Maka dapa disimpulkan bahwa variabel bebas jumlah siswa menghasilkan angka dibawah 0,05 , yang mana dapat diartikan pembentuk model lolos uji t. Sehingga berdasarkan hasil yang diperoleh dapat diambil keputusan bahwa variabel jumlah siswa (X5) berpengaruh secara signifikan terhadap variabel jumlah tarikan kendaraan roda 2 (Y1). Berdasarkan Tabel 3.15 diketahui model yang didapat memiliki harga koefisien determinasi (R2) Adjusted R Square sebesar 0,957. Hal tersebut menunjukkan sebanyak 93,8\% jumlah tarikan pergerakan kendaraan roda 2 dipengaruhi oleh jumlah siswa. Sedangkan sisanya $4,3 \%$ dijelaskan oleh variabel-variabel yang tidak dibahas dalam penelitian ini.

\section{Tarikan Kendaraan Roda 4}

Model persamaan tarikan kendaraan roda 4 yaitu $\mathrm{Y} 2=5,328+0,004 \mathrm{X} 5$ mendapatkan hasil uji serempak (uji F) menghasilkan angka signifikansi seperti pada Tabel 3.13 yaitu sebesar 0,009. Maka model analisis regresi pembentuk model lolos uji $\mathrm{F}$, dan dapat dikatakan signifikan. Kemudian berdasarkan pada Tabel 3.14 dapat diketahui bahwa hasil uji parsial (Uji t) bahwa angka signifikansi variabel bebas jumlah siswa (X5) sebesar 0,009. Maka dapa disimpulkan bahwa variabel bebas jumlah siswa menghasilkan angka dibawah 0,05 , yang mana dapat diartikan pembentuk model lolos uji t. Sehingga berdasarkan hasil yang diperoleh dapat diambil keputusan bahwa variabel jumlah siswa (X5) berpengaruh secara signifikan terhadap variabel jumlah tarikan kendaraan roda 4 (Y2). Berdasarkan Tabel 3.15 diketahui model yang didapat memiliki harga koefisien determinasi (R2) Adjusted R Square sebesar 0,973. Hal tersebut menunjukkan sebanyak 93,2\% 
jumlah tarikan pergerakan kendaraan roda 4 dipen garuhi oleh jumlah siswa. Sedangkan sisanya $2,7 \%$ dijelaskan oleh variabel-variabel yang tidak dibahas dalam penelitian ini.

\section{SIMPULAN}

Dapat disimpulkan bahwa jumlah tarikan pergerakan kendaraan di SMKN 1 Glagah Banyuwangi untuk kendaraan bermotor roda 2 sebanyak 1.292 kendaraan, roda 4 sebanyak 13 kendaraan, total roda 2 dan roda 4 sebanyak 1.303 kendaraan, SMKN 1 Banyuwangi untuk kendaraan bermotor roda 2 sebanyak 1.189 kendaraan, roda 4 sebanyak 14 kendaraan, total roda 2 dan roda 4 sebanyak 1.203 kendaraan, SMK PGRI 1 Giri Banyuwangi untuk kendaraan bermotor roda 2 sebanyak 759 kendaraan, roda 4 sebanyak 10 kendaraan, total roda 2 dan roda 4 sebanyak 769 kendaraan, dan SMK Sri Tanjung Banyuwangi untuk kendaraan bermotor roda 2 sebanyak 228 kendaraan, roda 4 sebanyak 8 kendaraan, total roda 2 dan roda 4 sebanyak 236 kendaraan.

Karakteristik sosial ekonomi dan perjalanan yang mendominasi adalah jumlah kepemilikan sepeda motor 1 unit dengan frekuensi 142 responden prosentase $43,2 \%$, jumlah kepemilikan mobil 0 unit dengan frekuensi 273 responden prosentase $83 \%$, jarak tempat tinggal ke sekolah yang lebih dari $5 \mathrm{~km}$ dengan frekuensi 126 responden prosentase $38,3 \%$, waktu perjalanan ke sekolah yang ditempuh lebih dari 15 menit dengan frekuensi 102 responden prosentase $31 \%$, moda transportasi menggunakan sepeda motor dengan frekuensi 301 responden prosentase 91,8\%.

Model tarikan pergerakan kendaraan yang didapat yaitu (1) tarikan kendaraan roda 2 dan roda $4 \mathrm{Y}=-163,104+0,722 \mathrm{X} 5, \mathrm{R} 2=0,958$ dengan jumlah siswa (X5) merupakan variabel bebas yang berpengaruh secara signifikan sebesar 95,8\% terhadap jumlah tarikan kendaraan roda 2 dan roda 4 (2) tarikan kendaraan roda $2 \mathrm{Y} 1=-169,085+0,719 \mathrm{X} 5, \mathrm{R} 2=0,957$ dengan jumlah siswa (X5) merupakan variabel bebas yang berpengaruh secara signifikan sebesar 95,7\% terhadap jumlah tarikan kendaraan roda 2 (3) tarikan kendaraan roda $4 \mathrm{Y} 2=$ $5,328+0,004 X 5, \mathrm{R} 2=0,973$ dengan jumlah siswa (X5) merupakan variabel bebas yang berpengaruh secara signifikan sebesar 97,3\% terhadap jumlah tarikan kendaraan roda 4 .

\section{DAFTAR RUJUKAN}

Chaira. 2017. Analisis Model Tarikan Perger akan Pada Sekolah Di Kota Meulaboh. (online), (http://jurnal.utu.ac.id/jtsipil/ar ticle/view/223/0) diakses 29 Maret 2019.

Mikkelsen. 2011. Metode Penelitian Partisi patoris Dan Upaya Pemberdayaan: Pan duan Bagi Praktisi Lapangan. Jakarta: Yayasan Pustaka Obor Indonesia.

Munawar, A. 2005. Dasar-Dasar Teknik Trans portasi. Jogjakarta: Beta Offset.

Ortũzar, J. \& Willumsen, L. 2011. Modelling Fourth Edition. England: John Willey \& Sons Ltd.

Priyatno, P. 2012. Cara Kilat Belajar Analisis Data dengan SPSS 20. Yogyakarta: C.V Andi Offset.

Raharjo, S. 2017. Uji Asumsi Klasik meng gunakan SPSS. (Online), (https://www. spssindonesia.com/search/label/Uji\%20 Asumsi\%20Klasik), diakses 14 Juli 2019. Simatupang, T. M. 1995. Pemodelan Sistem. Edisi 1. Klaten: Nindita.

Sugiyono. 2015. Metode Penelitian Kuantita tif, Kualitatif, dan Kombinasi (Mixed Methods). Bandung: Alfabeta

Tamin, O.Z. 2000. Perencanaan dan Pemod elan Transportasi. Edisi Kedua. Bandung: Institut Teknologi Bandung

Widiarti, S.F. 2017. Model Produksi Perjala nan Keluarga di Perumahan pinggir Kota Malang. Skripsi tidak diterbitkan. Fakultas Teknik Universitas Negeri Malang. 